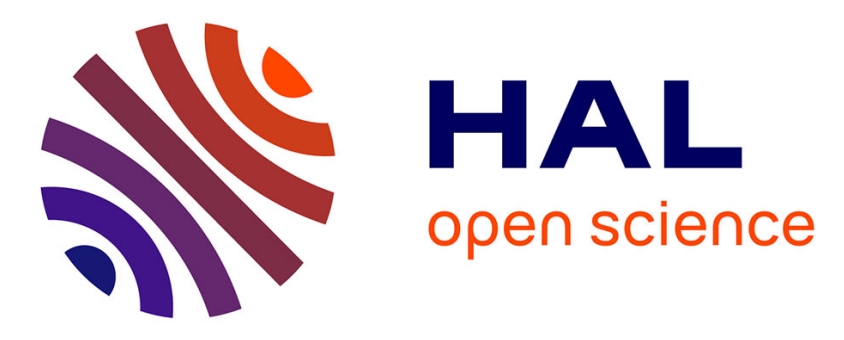

\title{
Investigation of solution acidity influence on the morphological structure and physical and mechanical properties of particle-reinforced tungsten alloys
}

Fangnao Xiao, Thierry Barriere, Gang Cheng, Qiang Miao, Shiwei Zuo, Shizhong Wei, Liujie Xu

\section{To cite this version:}

Fangnao Xiao, Thierry Barriere, Gang Cheng, Qiang Miao, Shiwei Zuo, et al.. Investigation of solution acidity influence on the morphological structure and physical and mechanical properties of particlereinforced tungsten alloys. International Journal of Advanced Manufacturing Technology, 2021, 116 (1-2), pp.439 - 447. hal-03456158

\author{
HAL Id: hal-03456158 \\ https://hal.science/hal-03456158
}

Submitted on 29 Nov 2021

HAL is a multi-disciplinary open access archive for the deposit and dissemination of scientific research documents, whether they are published or not. The documents may come from teaching and research institutions in France or abroad, or from public or private research centers.
L'archive ouverte pluridisciplinaire HAL, est destinée au dépôt et à la diffusion de documents scientifiques de niveau recherche, publiés ou non, émanant des établissements d'enseignement et de recherche français ou étrangers, des laboratoires publics ou privés. 


\section{The International Journal of Advanced Manufacturing Technology}

Investigation of solution acidity influence on the morphological structure, physical and mechanical properties of particles reinforced tungsten alloys

\section{--Manuscript Draft--}

Manuscript Number:

Full Title:

Keywords:

Corresponding Author:
Article Type:

JAMT-D-20-03191R1

Investigation of solution acidity influence on the morphological structure, physical and mechanical properties of particles reinforced tungsten alloys

Original Research

Particle reinforced tungsten alloy; Doping zirconia; Yttria - stabilized zirconia; mechanical property.

Fangnao Xiao

Femto-st Institute

Besancon, FRANCE

\section{Corresponding Author Secondary}

Information:

Corresponding Author's Institution:

Femto-st Institute

\section{Corresponding Author's Secondary}

Institution:

First Author:

Fangnao Xiao

First Author Secondary Information:

Order of Authors:

\begin{tabular}{|l|}
\hline Fangnao Xiao \\
\hline Thierry Barriere \\
\hline Gang Cheng \\
\hline Qiang Miao \\
\hline Shiwei Zuo \\
\hline Shizhong Wei \\
\hline Liujie Xu \\
\hline
\end{tabular}

Order of Authors Secondary Information:

Funding Information:

\begin{tabular}{|c|c|}
\hline $\begin{array}{l}\text { National Natural Science Foundation of } \\
\text { China } \\
\text { (U2004180) }\end{array}$ & Prof. Liujie Xu \\
\hline $\begin{array}{l}\text { National Natural Science Foundation of } \\
\text { China } \\
(51874185)\end{array}$ & Prof. Qiang Miao \\
\hline $\begin{array}{l}\text { Nanjing university of aeronautics and } \\
\text { astronautics PhD short-term visiting } \\
\text { scholar project } \\
\text { (190107DF06) }\end{array}$ & Mr. Fangnao Xiao \\
\hline
\end{tabular}

Abstract:

Yttria - stabilized zirconia particles reinforced tungsten alloys were fabricated by using azeotropic distillation process coupled with powder metallurgy techniques. The influence of $\mathrm{pH}$ value of the original solution on the precursor powders' morphology, wear and mechanical properties of alloys were deeply studied. It showed that the precursor' powder synthesized under solution with $\mathrm{pH}$ of 2 possesses finer particles' size. The grain sizes of tungsten reinforced alloys obtained with different $\mathrm{pH}$ values varies from 2 to $6 \mu \mathrm{m}$, extremely smaller than that of pure tungsten. When $\mathrm{pH}$ value increases from 2 to 8 , more and more bonding zirconia particles are obtained. The reinforced tungsten alloy prepared based on the solution of $\mathrm{pH}$ equal to 2 have a better morphological and mechanical properties than the other two alloys prepared based on the solution of $\mathrm{pH}$ values of 5 and 8 , respectively. The wear resistance of the reinforced tungsten alloy increases firstly, then decreases with the doping amount of zirconia 
particles. It is confirmed that the $\mathrm{pH} 2$ value and chemical composition of the tungsten alloy with 3.0 wt. \% $\mathrm{Zr}(\mathrm{Y}) \mathrm{O} 2$ exhibits the best wear resistance. The mechanical properties of the particle reinforced tungsten alloy are improved with the decrease of $\mathrm{pH}$ value. The ultimate compressive strength and ultimate strain value of $\mathrm{pH} 2$ reach to $1009 \mathrm{MPa}$ and 0.23 , respectively. The evolution of the relative density and associated porosity increases with the $\mathrm{pH}$ value. The abrasion mechanism was analyzed in detail. 


\section{Response to Editor and Reviewer Comments:}

Ref. No.: JAMT-D-20-03191

Title: Investigation of solution acidity influence on the morphological structure, physical and mechanical properties of particles reinforced tungsten alloys.

We greatly appreciate the work of the editor and the referees in reviewing this manuscript. We have addressed the issue indicated in the review reports. The suggestion of the reviewer has been taken into account in the revised manuscript. The improvement of the revision is marked in red.

Reviewer \#2: In this work, the yttria - stabilized zirconia particles $(\mathrm{Zr}(\mathrm{Y}) \mathrm{O} 2)$ strengthened tungsten alloys $(\mathrm{W}-\mathrm{Zr}(\mathrm{Y}) \mathrm{O} 2)$ were developed via azeotropic distillation method combined with powder metallurgy techniques, but the content of the present work is not new. It is well known that the wear resistance of $\mathrm{W}-\mathrm{Zr}(\mathrm{Y}) \mathrm{O} 2$ alloy has been widely reported. The results in this work are not enough, which can not attract the readers of JAMT. In addition, the manuscript is also not well prepared.

Response: We have improved the manuscript by taking into account your comments. We have added new contents on the porosity, mechanical property and wear resistance of the reinforced $\mathrm{W}$ alloys in function of $\mathrm{pH}$ value. The revised manuscript is enriched and the quality of the paper is enhanced. We think it is now suitable to be published in JAMT.

Reviewer \#4: The following remarks seek careful consideration while revising the manuscript. The paper is returned with minor-modification decision to the authors according to the following comments:

Thanks for your excellent work to improve the quality of this paper. Your comments were carefully considered and some modifications were added in this revised manuscript.

(1) The English language of the paper must be carefully polished before any proceeds 
with the publication. There are still many typo and syntax errors remained and here some examples are presented; however, the errors in the whole text is not listed below:

--then decreases with increase in the doping amount of $\mathrm{Zr}(\mathrm{Y}) \mathrm{O} 2$. It is confirmed that the $=>$ then decreases with an increase in the doping amount of $\mathrm{Zr}(\mathrm{Y}) \mathrm{O} 2$. It is confirmed that the

--exhibits the highest wear resistance. The abrasion mechanism was analysed in details. => exhibits the highest wear resistance. The abrasion mechanism was analyzed in detail.

--Tungsten alloys have been widely used in the defence industry, nuclear reactor, => Tungsten alloys have been widely used in the defense industry, nuclear reactor,

--The past several years, many of liquid - liquid $(\mathrm{L}-\mathrm{L})$ methods were introduced $=>$ In the past several years, many of liquid - liquid (L - L) methods were introduced

--of precursor powders were analysed. Proper calcination process was determined => of precursor powders were analyzed. The proper calcination process was determined

Response: Thank you for pointing out the typo and syntax errors. Your comments were taking into account in the revised manuscript. Moreover, the whole article was carefully checked for spelling and format style. The revised manuscript was checked to avoid the plagiarism.

(2) To eliminate confusion on the sample fabrication, it is recommended that a separate table of sample fabrication and designation be added into the revised context. It can clearly show the types of fabricated samples with the applied parameters.

Response: Thank you for your suggestions. The preparation process of the samples, associated with the processing parameters was completely explained in the revised paper and in Fig. 1.

(3) One deficiency that existed in the text is the given evidence for each test or 
experiment is not consistent with others. The authors must follow the same manner to present results in the tables and figures. If authors fabricated different samples with various parameters, the results of all must be given to the readers for better comparison and for convincing based on the given discussions.

Response: Thank you for your suggestions. In Section 2, all the tests were described, including the dimension of the specimen, the testing standard and experimental parameters. All the figures and tables were explained in detail in the text. The manuscript was carefully revised to provide a height-level description.

(4) XRD patterns for all prepared specimens must be included to show the phase transformations and to prove the claim on the grain size difference. According to the text "The grain sizes of $\mathrm{W}-\mathrm{Zr}(\mathrm{Y}) \mathrm{O} 2$ alloys prepared with the solutions of different $\mathrm{pH}$ values are in the range of $2-6 \mu \mathrm{m}$, much smaller than that of pure tungsten", this is necessary.

Response: Thank you for your suggestions. The alloys prepared under $\mathrm{pH}=2$ possessed the best microstructure and were analyzed by XRD, as shown in Fig. 6. The alloys prepared under $\mathrm{pH}=5$ and 8 were not analyzed due to the poor physical properties.

(5) In the introduction part, it is recommended to add some discussion on the metal matrix composites strengthened with ceramic particles. The challenges and merits could be discussed briefly. The authors may want to review the following refs on the title:

[a] Ceramics International 39 (6), 6099-6106

[b] Ceramics International 44 (3), 3128-3133

[c] International Journal of Damage Mechanics 24 (2), 245-262

[d] Materials Science and Engineering: A 598, 162-173

Response: Thank you for your comment. These relevant references were added in the revised paper. 
(6) For the reference part, it is recommended to exclude the obsolete refs and substitute newly published refs after 2010. In the meantime, the number of the reviewed refs are too limited. Expanding the reviewed list is necessary.

Response: Thank you for your comment. Some recent publications were added in the revised manuscript. The papers published before 2010 were excluded in the reference list.

(7) Expanding the discussion on the Fig. 2 results is recommendation.

Response: Some more discussions were provided according to your recommendation.

(8) Discussion on the porosity and its measurement on the different fabricated samples is recommended as well.

Response: The relative density and associated porosity versus $\mathrm{pH}$ value were added in the revised manuscript.

(9) Fig. 5 seems to be redundant. Just claiming based on the reference would be enough.

Response: Based on your suggestion, the fig. 5 was removed.

(10) fig. 7, the stress-strain curves showed the raw data and need to be corrected. Presenting the uncorrected data is not beneficial and somehow misleading especially in the case of elongation comparison.

Response: The curves in Fig. 7 were improved according to your suggestion. The uncorrected values were replaced, as shown in Fig. 8.

Reviewer \#5: 1. please provide error bar to Figure 7. What is the experiment setup and sample dimensions of compression test?

Thanks for your comments to improve the quality of this paper. Your comments were carefully considered and some modifications were added in this revised manuscript. 
Response: The error bar of strain and stress was added in the curves, as shown in Fig. 8. The experiment setup and specimen dimensions were described in Section 2 of the revised paper.

2. It would be interesting to see the effect of $\mathrm{pH}$ on material tensile properties as well. Response: The elaborated specimens are too small to perform the international standard tensile test. In the future, the reinforced powders will be manufactured with industrial pilot to obtain the larger dimension specimens by SPS. 
Apr. $15^{\text {th }} 2021$

To

Prof. Andrew Yeh-Ching Nee, Ph.D.

Editor-in-Chief: The International Journal of Advanced Manufacturing Technology

Dear Sir,

I am pleased to submit the revised version of our research article entitled "Investigation of solution acidity influence on the morphological structure, physical and mechanical properties of particles reinforced tungsten alloys".

The reviewers' comments are addressed in the revised manuscript and the responses are appended herewith for your reference.

We believe that the improved manuscript is now appropriate for publication in Advanced Manufacturing Technology.

This manuscript has not been published nor under consideration for publication elsewhere. We have no conflicts of interest to disclose.

Thank you for your consideration. 
Investigation of solution acidity influence on the morphological structure, physical and mechanical properties of particles reinforced tungsten alloys

Fangnao Xiao ${ }^{\mathrm{a}, \mathrm{b}}$, Thierry Barriere ${ }^{\mathrm{a}}$, Gang Cheng ${ }^{\mathrm{c}}$, Qiang Miao ${ }^{\mathrm{b}}$, Shiwei Zuo ${ }^{\mathrm{b}}$, Shizhong Wei ${ }^{\mathrm{d} *}$, Liujie $\mathrm{Xu}^{\mathrm{d} *}$

a Université Bourgogne Franche-Comté, FEMTO-ST Institute, CNRS/UFC/ENSMM/UTBM, Department of Applied Mechanics, 25000 Besançon, France

${ }^{\mathrm{b}}$ College of Material Science and Technology, Nanjing University of Aeronautics and Astronautics, 29 Yudao Street, Nanjing 210000, China

c INSA CVL, Université Tours, Université Orléans, LaMé, 3 rue de la Chocolaterie, BP 3410, 41034 Blois Cedex, France

${ }^{\mathrm{d}}$ National Joint Engineering Research Center for abrasion control and molding of metal materials, Henan University of Science and Technology, Luoyang 471003, China

E-mail of Corresponding author:

miaoqiang@nuaa.edu.cn (Qiang Miao)

wsz@haust.edu.cn (Shizhong Wei)

xlj@haust.edu.cn (Liujie Xu) 


\begin{abstract}
Yttria - stabilized zirconia particles reinforced tungsten alloys were fabricated by using azeotropic distillation process coupled with powder metallurgy techniques. The influence of $\mathrm{pH}$ value of the original solution on the precursor powders' morphology, wear and mechanical properties of alloys were deeply studied. It showed that the precursor' powder synthesized under solution with $\mathrm{pH}$ of 2 possesses finer particles' size. The grain sizes of tungsten reinforced alloys obtained with different $\mathrm{pH}$ values varies from 2 to $6 \mu \mathrm{m}$, extremely smaller than that of pure tungsten. When $\mathrm{pH}$ value increases from 2 to 8 , more and more bonding zirconia particles are obtained. The reinforced tungsten alloy prepared based on the solution of $\mathrm{pH}$ equal to 2 have a better morphological and mechanical properties than the other two alloys prepared based on the solution of $\mathrm{pH}$ values of 5 and 8 , respectively. The wear resistance of the reinforced tungsten alloy increases firstly, then decreases with the doping amount of zirconia particles. It is confirmed that the $\mathrm{pH} 2$ value and chemical composition of the tungsten alloy with 3.0 wt. \% $\mathrm{Zr}(\mathrm{Y}) \mathrm{O}_{2}$ exhibits the best wear resistance. The mechanical properties of the particle reinforced tungsten alloy are improved with the decrease of $\mathrm{pH}$ value. The ultimate compressive strength and ultimate strain value of $\mathrm{pH} 2$ reach to $1009 \mathrm{MPa}$ and 0.23 , respectively. The evolution of the relative density and associated porosity increases with the $\mathrm{pH}$ value. The abrasion mechanism was analyzed in detail.
\end{abstract}

Keywords: Particle reinforced tungsten alloy; Doping zirconia; Yttria - stabilized zirconia; mechanical property

\title{
Nomenclature
}
AMT
Ammonium metatungstate
APT
Ammonium paratungstate
DBTT
Ductile-brittle transition temperature
DSC
Differential scanning calorimeter
EDS
Electron dispersive spectroscopy 
HV

HR - TEM High - resolution transmission electron microscopy

ODS - W Oxide particles dispersion - strengthened tungsten

$\mathrm{L}-\mathrm{L}$

SEM

S - L

TGA

XRD
Liquid - liquid

Scanning electron microscope

Solid- liquid

Thermogravimetric analysis

$\mathrm{X}$ - ray diffraction

\section{Introduction}

Tungsten and its alloys are largely employed in the defense and nuclear industry due to their high melting point, hardness and strength at various temperatures [1-4]. It possesses a high ductile-brittle transition temperature (DBTT) with a low recrystallization temperature, which negatively influences its physical behavior $[5,6]$. In order to enhance the tungsten alloys' physical behavior, the research on oxide particle dispersion - strengthened tungsten (ODS - W) alloy, is attracted more and more attentions [7-9], because these oxide particles could decrease DBTT and increase the recrystallization temperature [10-12].

With the recent progress of the powder metallurgy, the morphological and mechanical properties of particle reinforced tungsten alloys are relied on tungsten powder quality $[13,14]$. High - energy ball milling of the mixed powders with pure tungsten and oxide particles is an efficient method for fabricating ultrafine doped tungsten powders. Prolonged milling time may lead to introduction of detrimental contaminants [15], inhomogeneous distribution of oxide dispersion particles and high internal stresses [16]. Solid-liquid methods were selected to obtain excellent doped tungsten powder based on the raw materials of ammonium paratungstate (APT) and soluble metal salts $[11,17]$. APT powder is slightly soluble and does not react with soluble metal salts. The reaction occurs only on the surface of APT powder particles, resulting in the formation of tungsten particle aggregates [11] and the heterogeneous distribution of oxide particles [17]. 
Many liquid - liquid (L - L) methods were investigated to prepare the particle reinforced tungsten alloys [18-22]. The previous researches focus mainly on the tensile, compressive and torsional properties of these alloys [2]. Less research concerned the interactions of the precursor powders on the morphological properties of alloys obtained by L - L methods. Microstructural characterization of these doped ceramic particles affects the microstructural evaluation, strength and wear resistance of metal matrix composites. A. Heidarzadeh et al. [23] reported that the presence of nanoparticles increased the proportion of the continuous dynamic recrystallization compared to the discontinuous mechanism during grain structure formation. A. H. Monazzah et al. [24] indicated that intrinsic toughening had influence on the fracture resistance of composite materials based on inherent resistance of its microstructure to crack nucleation. The microstructure includes the morphology and size of reinforced phase particle. F. Xiao et al. [25] investigated the microstructure, compressive properties and wear resistance of $\mathrm{W}-\mathrm{ZrO}_{2}$ alloys by different preparation techniques. The results indicate that the smaller the $\mathrm{ZrO}_{2}$ particle, the higher the compressive properties and wear resistance.

In particle strengthened composite materials, the main topics have been conducted on providing uniformly dispersed hard reinforcements in matrix [26]. These uniformly oxide particle would result in distinguished properties caused by homogenous structure, high interfacial strength and uniform deformation of composite materials [27].

The solutions with different acidities greatly influence on the reduced tungsten powders [25]. The researches concerning the effect of the solution's $\mathrm{pH}$ value on precursor powders, physical properties of tungsten alloys have to be studied in detail.

In this research, in order to determine the proper $\mathrm{pH}$ value for fabricating the uniform distribution of ultrafine oxide particle in tungsten matrix, the doped alloys fabricated with different $\mathrm{pH}$ values of 2, 5 and 8 were prepared. The morphologies of precursor powders were analyzed. The proper calcination process was determined through thermogravimetric analysis and differential scanning calorimetry. The 
Table 1. The chemical composition of the tungsten alloy specimens (wt. \%).

\begin{tabular}{ccccc}
\hline Specimens & Solution & $\mathbf{W}$ & $\mathbf{Z r O}_{2}$ & $\mathbf{Y}_{2} \mathbf{O}_{3}$ \\
\hline Pure W & 2 & 100 & 0 & 0 \\
pH 2 & 2 & 96.62 & 3.0 & 0.38 \\
pH 5 & 5 & 96.62 & 3.0 & 0.38 \\
pH 8 & 7 & 96.62 & 3.0 & 0.38 \\
\hline
\end{tabular}

Fig. 1 illustrated the process flow diagram of tungsten alloys with the associated processing parameters. The $\mathrm{Y}\left(\mathrm{NO}_{3}\right)_{3} \cdot 6 \mathrm{H}_{2} \mathrm{O}$ and $\mathrm{Zr}\left(\mathrm{NO}_{3}\right)_{4} \cdot 5 \mathrm{H}_{2} \mathrm{O}$ solutions were mixed 
under continuous stirring and heated to $90{ }^{\circ} \mathrm{C}$ until precipitates appeared. The $\left(\mathrm{NH}_{4}\right)_{6} \mathrm{H}_{2} \mathrm{~W}_{12} \mathrm{O}_{40} \cdot x \mathrm{H}_{2} \mathrm{O}$ solution was added dropwise to previous solution. The $\mathrm{pH}$ value was measured using nitric acid or ammonia solution and stirring during $5 \mathrm{~h}$ at a room temperature $\left(22^{\circ} \mathrm{C}\right)$. The ethanol was introduced into the mixed solution as a dispersant. The mixture was continuously heated until the precursor powder appeared. The synthesized precursor powders were calcined at $550{ }^{\circ} \mathrm{C}$ for $4 \mathrm{~h}$ and reduced by following two reduction processes $750{ }^{\circ} \mathrm{C} \times 2 \mathrm{~h}+900{ }^{\circ} \mathrm{C} \times 4 \mathrm{~h}$ under hydrogen atmosphere in order to achieve $\mathrm{W}-\mathrm{Zr}(\mathrm{Y}) \mathrm{O}_{2}$ powders.

The $\mathrm{W}-\mathrm{Zr}(\mathrm{Y}) \mathrm{O}_{2}$ powders were compressed into an elastomeric mould at the pressure of $350 \mathrm{MPa}$ during 30 minutes using cold isostatic press. The cylindrical specimens were obtained with $30 \mathrm{~mm}$ long and a diameter of $20 \mathrm{~mm}$. The specimens were sintered in an induction furnace under hydrogen atmosphere. The pre - sintering was performed at $1250{ }^{\circ} \mathrm{C}$ during $2 \mathrm{~h}$. The final sintering was set at $2400{ }^{\circ} \mathrm{C}$ during 4 h.

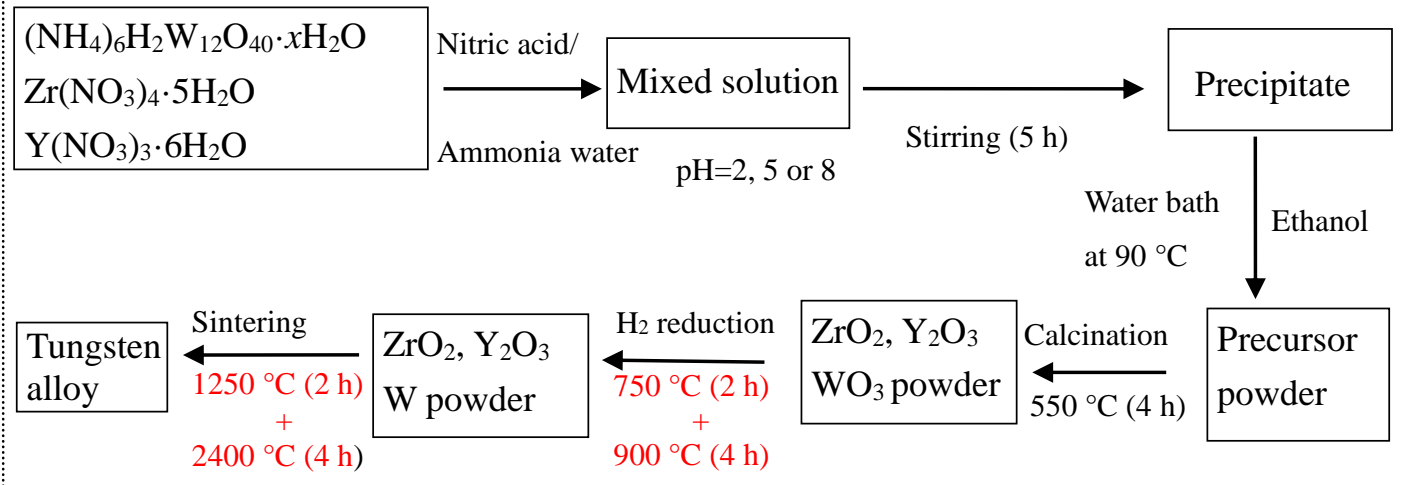

Fig. 1. Illustration of process flow diagram of tungsten alloys with the processing parameters.

\subsection{Methods}

The absolute density of the studied materials was determined according to ASTM B962-14 standard using Archimedes principle with ten repeated measurements in the same experimental conditions. The relative density $\xi$ was determined by the following relation [20]: 


$$
\xi=\rho / \rho_{0}
$$

where $\rho$ and $\rho_{0}$ are the absolute and theoretical density of material, respectively.

The material porosity was determined as follows:

$$
P=(1-\xi) \times 100 \%
$$

where $P$ is the material porosity.

Vickers hardness was measured using a micro - Vickers hardness testing equipment (HVS - $1000 \mathrm{~A}$ ) with an imposed load of $200 \mathrm{~g}$ for $20 \mathrm{~s}$ according to the ASTM E384 test method. The Vickers hardness value was an average of 10 random measurements.

Ten tests were performed using universal compression testing equipment (AG $\mathrm{I} 250 \mathrm{KN}$ ) at room temperature with a crosshead speed of $1.0 \mathrm{~mm} / \mathrm{min}$. Cylindrical compression specimens with a diameter and length of 6 and $10 \mathrm{~mm}$.

Based on the ASTM B328 standard, the wear property was characterized using a pin - on - disc wear test (ML - 100 type). The wear test was repeated ten times. Different grit alumina waterproof - abrasive sandpapers of 240, 360, 600 and 800, respectively, were imposed with $40 \mathrm{~N}$. The cylindrical specimens are: diameter $6 \mathrm{~mm}$ $\times$ length $20 \mathrm{~mm}$. At the end of the tests, the specimens were washed with ethanol and weighted using an analytical balance.

The microstructure and chemical composition of powder and alloy specimens were analyzed by Scanning Electron Microscope (SEM, VEGA - SBH) according to the ASTM E2142-08 standard. An energy - dispersive X - ray spectrometry (EDS) was employed. The reaction of precursor powders was analyzed by using NETZSCH STA 409 PC/PG thermal analyser. Thermogravimetric analysis (TGA) was performed based on the ASTM EE228-11 standard. Differential scanning calorimeter (DSC) was effectuated according to the ASTM D3418 standard. High-resolution transmission electron microscopy (HR - TEM) was used to analyze the microstructure of the material with a Phillips FEI Titan 80-300. 


\section{Results and discussions}

\subsection{Investigation of precursor powders synthesized under various $\mathrm{pH}$ values}

Fig. 2 shows the SEM images of powders synthesized through azeotropic distillation method corresponding to $\mathrm{pH}$ value of 2, 5 and 8 . For $\mathrm{pH} 2$, the particles possess granular structure with a size of approximately $1-5 \mu \mathrm{m}$, while several particles are with the shape of plate, as shown in Fig. 2 a). For $\mathrm{pH} 5$, the microstructure of the powder is mainly in the shape of plate and block, as shown in Fig. 2 b). The length of the plate-like particle is less than $10 \mu \mathrm{m}$, the surface is smooth and the dispersion is well. For $\mathrm{pH} 8$, the particles are mainly in the form of block with a size of $3-8 \mu \mathrm{m}$, as shown in Fig. $2 \mathrm{c}$ ). As a conclusion, the microstructure of the materials was significantly affected by the $\mathrm{pH}$ value of solution.

The particle size increases and the morphology changed greatly with the $\mathrm{pH}$ value of the solution. Different polytungstate species were existed in solutions with various $\mathrm{pH}$ values. The reaction mechanism concerning the polytungstate species with $\mathrm{H}^{+} / \mathrm{OH}^{-}$were discussed in detail [25].
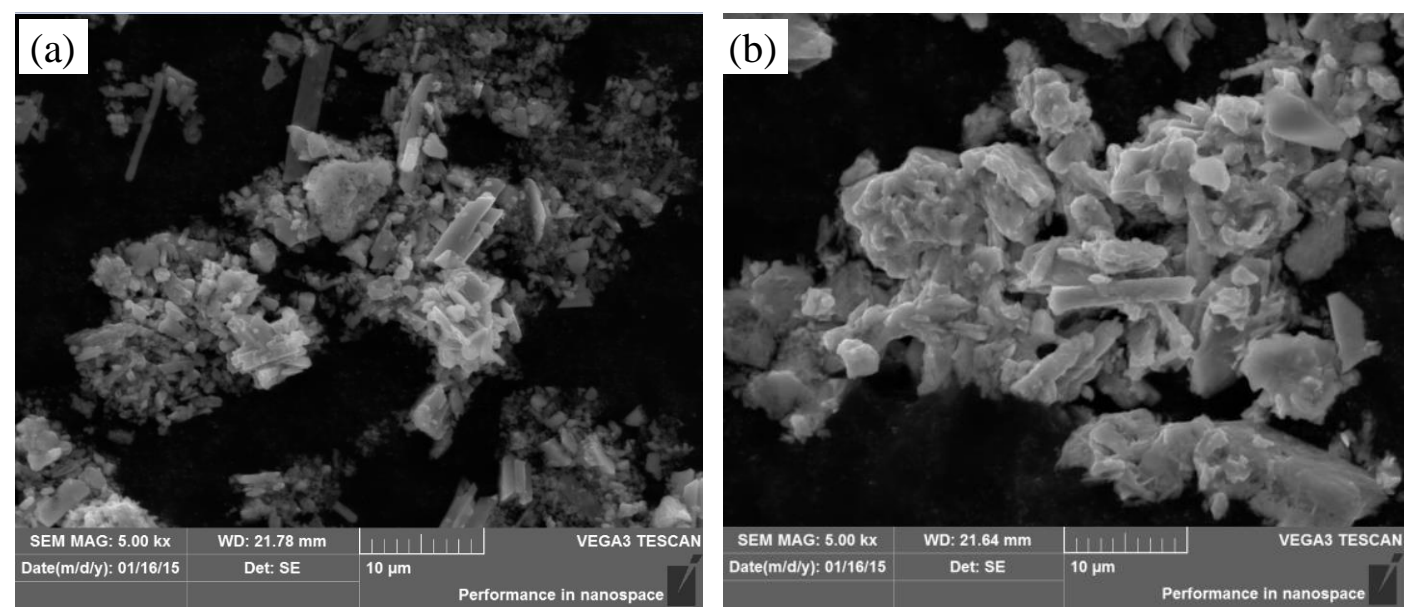


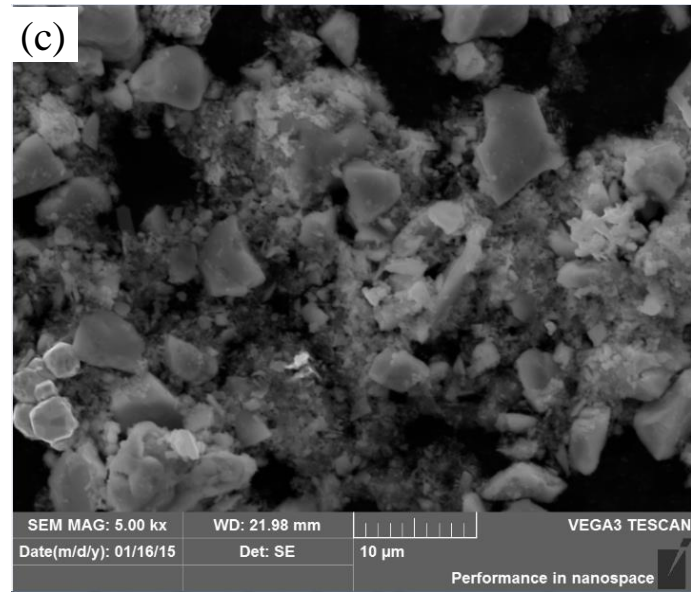

Fig. 2 SEM images of the precursor powders synthesized under: a) $\mathrm{pH}$ 2, b) $\mathrm{pH} 5$ and, c) $\mathrm{pH} 8$.

\subsection{Analysis of calcined and reduced powders conducted on doped $\mathrm{pH} 2$ precursor powder}

The $\mathrm{pH} 2$ precursor powder particle possesses finer particle structure according to the analysis in section 3.1. The TGA and DSC analyses were carried out at a heating rate of $1{ }^{\circ} \mathrm{C} / \mathrm{min}$ in the temperature range of $20-900{ }^{\circ} \mathrm{C}$. The calcination process was determined in an $\mathrm{Ar}$ atmosphere. In Fig. 3, when the temperature raised to $140-160{ }^{\circ} \mathrm{C}$, a small range of endothermic peak appeared caused by the evaporation of the adsorbed water in the material. When heated to the temperature range of about $240 \sim 340{ }^{\circ} \mathrm{C}$ with the peak at $308.3{ }^{\circ} \mathrm{C}$, there was an obvious exothermic peak caused by the decomposition of reaction product $\mathrm{NH}_{4} \mathrm{NO}_{3}$. Hunyadi et al. [28] described the similar phenomena that $\mathrm{NH}_{3}$ and $\mathrm{H}_{2} \mathrm{O}$ were released from AMT with an exothermic reaction from 240 to $340{ }^{\circ} \mathrm{C}$. When the temperature increased to about $360^{\circ} \mathrm{C}$, sharp endothermic peak appeared due to crystalline water loss in the reaction products.

The exothermic peak occurring at $412.7^{\circ} \mathrm{C}$ was attributed to the transformation from $\mathrm{WO}_{3}$ amorphous to $\mathrm{WO}_{3}$ crystal. When the temperature increased to $550{ }^{\circ} \mathrm{C}$, the total weight loss of the specimens was about $7.9 \%$. When the temperature continued to increase, the TGA curve in Fig. 3 showed that the weight loss was almost unchanged, which indicated that the precursor powder was almost completely 
decomposed at $550{ }^{\circ} \mathrm{C}$. The linear decrease of the total weight loss was observed in the range of $100-900^{\circ} \mathrm{C}$, corresponding to the calcination process.

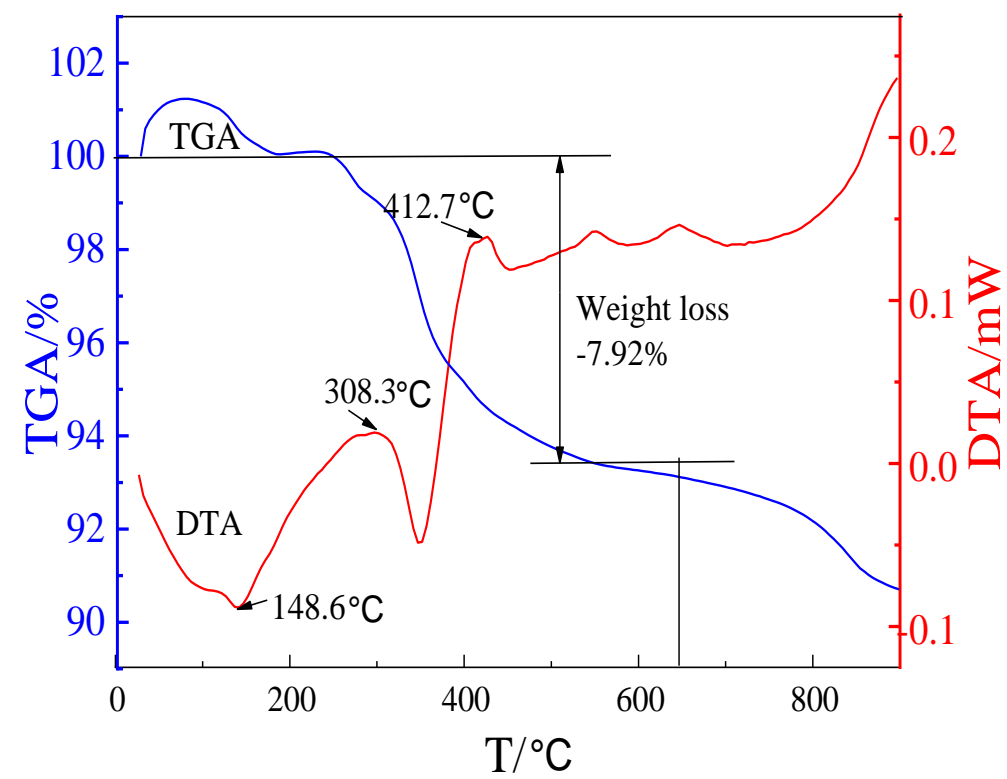

Fig. 3 TGA - DSC curves of doped precursor powder synthesized under pH 2.

The pH 2 specimens were analyzed by HR - TEM to quantify the particle morphology and phase structure. The obtained images of the powder reduced after $750{ }^{\circ} \mathrm{C} \times 2 \mathrm{~h}+900^{\circ} \mathrm{C} \times 4 \mathrm{~h}$ were shown in Fig 4 a). Based on Fig. 4 a), the reduced powder were regularly in a small spherical particle shape and well dispersed. The size was about $40 \mathrm{~nm}$, which belonged to nano-sized particles. The selected area A corresponded to Fig. 4 b). As the nanoparticle under selected area B consisted of the containing - $\mathrm{Zr}$ phase and containing - $\mathrm{Y}$ phase through mixing these two phases firstly, the selected area B corresponded to Figs. 4 c) and, d). The reduced powder particles were calibrated with lattice fringes, as shown in Figs. 4 b), c) and d). The measured spacing of lattice fringes were $0.2460 \mathrm{~nm}, 0.3227 \mathrm{~nm}$ and $0.3448 \mathrm{~nm}$ close to the spacing of $\mathrm{W}(200), \mathrm{ZrO}_{2}(-111)$ and $\mathrm{Y}_{2} \mathrm{O}_{3}$ (202) crystal planes of PDF\#47-1319, PDF\#65-2357 and PDF\#44-0399, respectively [29]. As analysis above, the reduced $\mathrm{pH} 2$ powders were composed of tungsten and $\mathrm{ZrO}_{2}-\mathrm{Y}_{2} \mathrm{O}_{3}$ nano-sized particles.

The formation of $\mathrm{ZrO}_{2}-\mathrm{Y}_{2} \mathrm{O}_{3}$ doped powder was related to the mechanism of doped powder in the hydrogen reduction process. $\mathrm{Y}$ and $\mathrm{Zr}$ atoms were always in the 
form of oxide during high - temperature reduction. Solid tungsten oxide would volatilize and then formed hydroxide $\mathrm{WO}_{2}(\mathrm{OH})_{2}$ with high volatility. Hydroxide $\mathrm{WO}_{2}(\mathrm{OH})_{2}$ would deposit on the surfaces of the neighbor tungsten oxide with low valence states or doped $\mathrm{Y}_{2} \mathrm{O}_{3}-\mathrm{ZrO}_{2}$ particles [30]. The growth rate increase and "volatilization - deposition" would make particles full growth in the process [31, 32]. The $\mathrm{Y}_{2} \mathrm{O}_{3}-\mathrm{ZrO}_{2}$ particles provided plenty of crystal nucleus, which hindered the growth of tungsten particles and eventually generated the nano-sized doped tungsten powders.
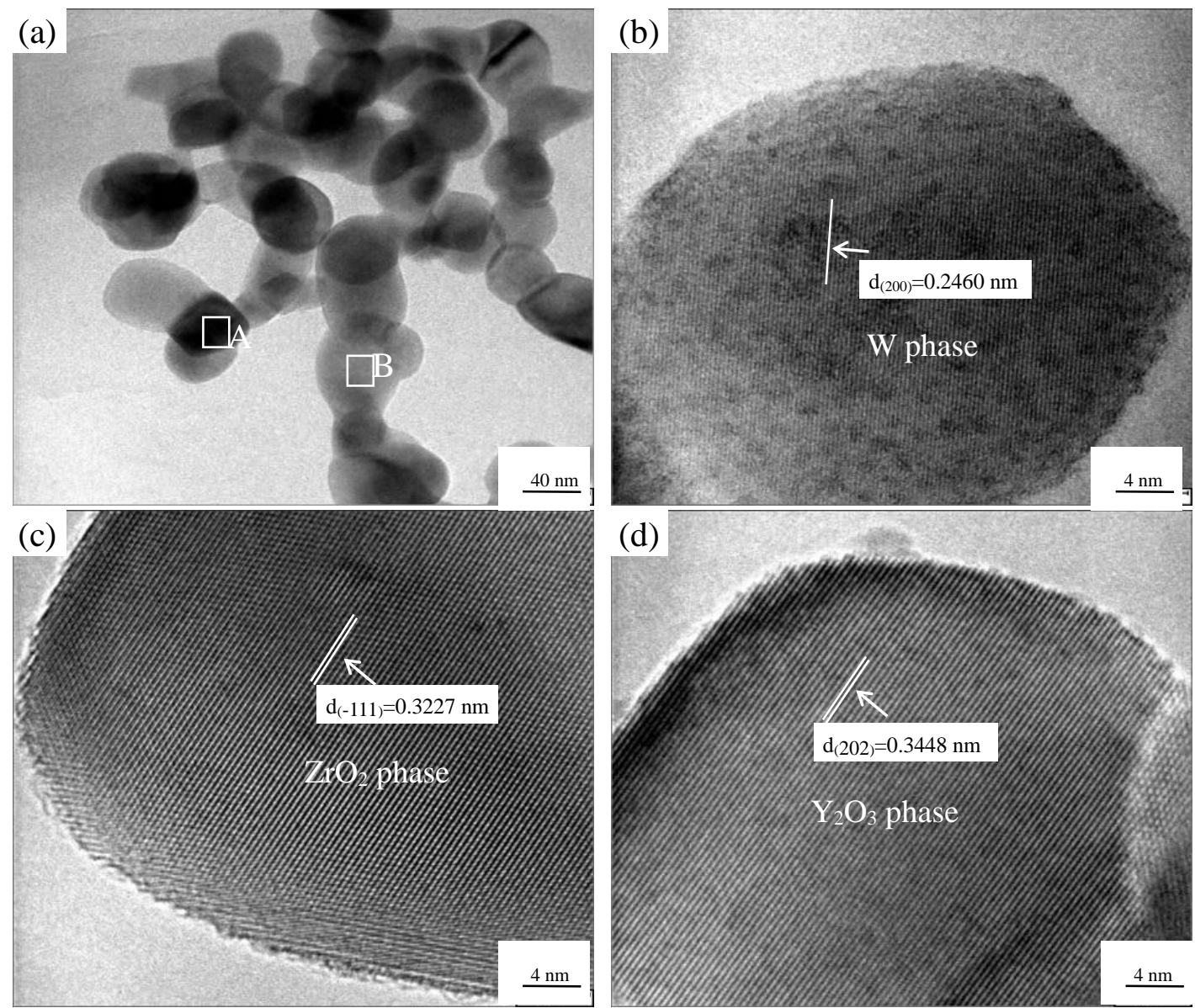

Fig. 4 HR - TEM image and diffraction fringes of reduced powders corresponding to test case $\mathrm{pH} 2$ for doped W sample [29]: a) HR - TEM image of reduced powders, b) Diffraction fringes of $\mathrm{W}$ powder particle, c) Diffraction fringes of $\mathrm{ZrO}_{2}$ powder particle and, (d) Diffraction fringes of $\mathrm{Y}_{2} \mathrm{O}_{3}$ powder particle. 

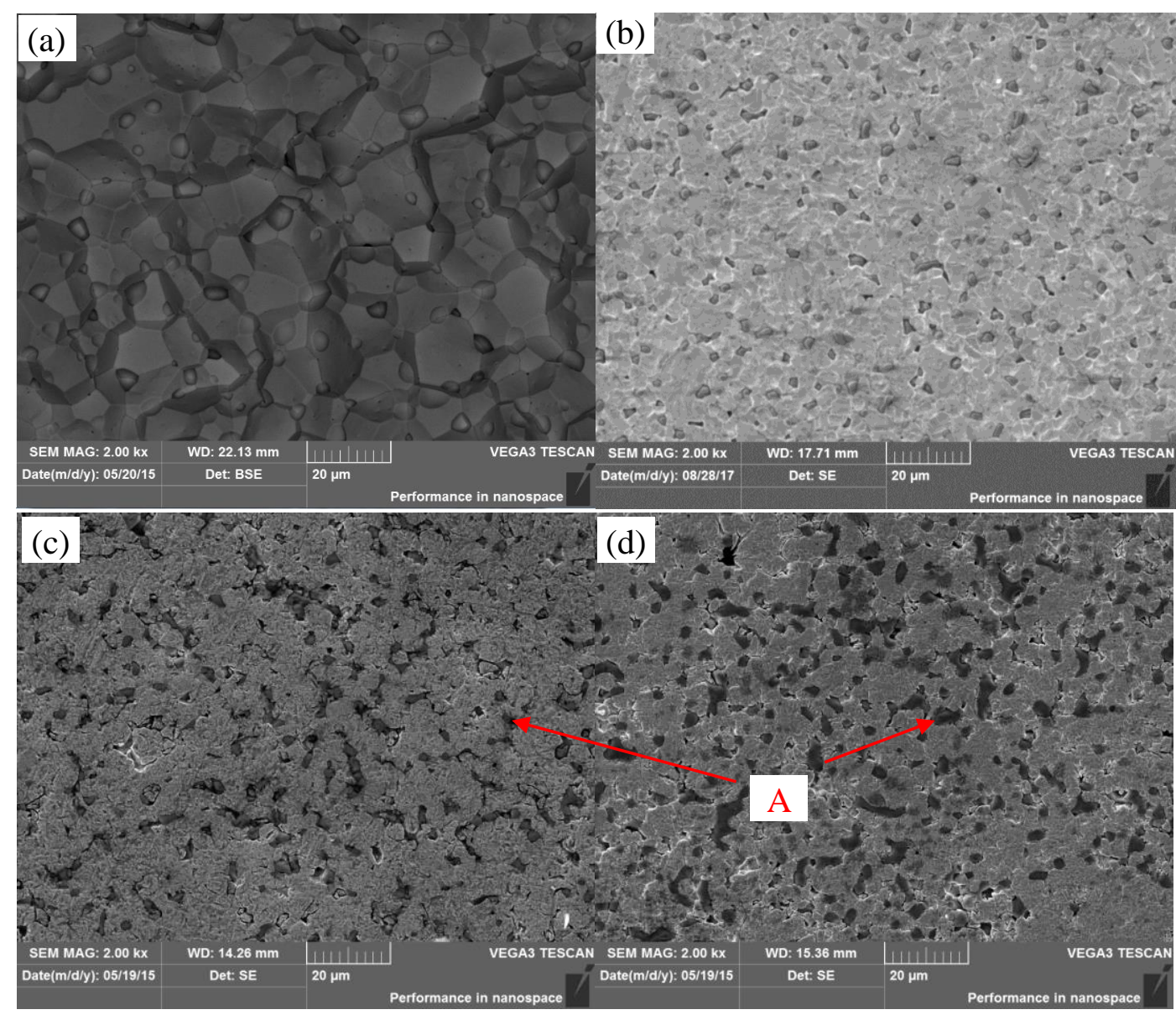
The grain size of irregular particles is about $10-15 \mu \mathrm{m}$. Based on Figs. 5 (b - d), there are many pores among alloys mainly caused by the pressureless sintering method. The alloy density is much lower compare to the pure W. In these alloys, the grain size is in the range of $2-6 \mu \mathrm{m}$, much smaller than pure $\mathrm{W}$ due to the effect of grain refinement. Based on the SEM images, these particles are mostly located at $\mathrm{W}$ grain boundaries.

When the alloy was prepared with $\mathrm{pH} 2$, the $\mathrm{Zr}(\mathrm{Y}) \mathrm{O}_{2}$ particles were smaller in size and more uniformly distributed. In the case of $\mathrm{pH} \mathrm{5,} \mathrm{the} \mathrm{occurrence} \mathrm{of} \mathrm{some}$ bonding $\mathrm{Zr}(\mathrm{Y}) \mathrm{O}_{2}$ particles can be observed, as marked with an arrow A. For $\mathrm{pH} 8$, more and more bonding particles were observed, which was not conducive to improve the alloy properties. Based on the EDS results, the black phase is corresponding to $\mathrm{Zr}(\mathrm{Y}) \mathrm{O}_{2}$ consisting of the elements: $\mathrm{Zr}$, $\mathrm{Y}$ and $\mathrm{O}$, as shown in Fig 5 e). 


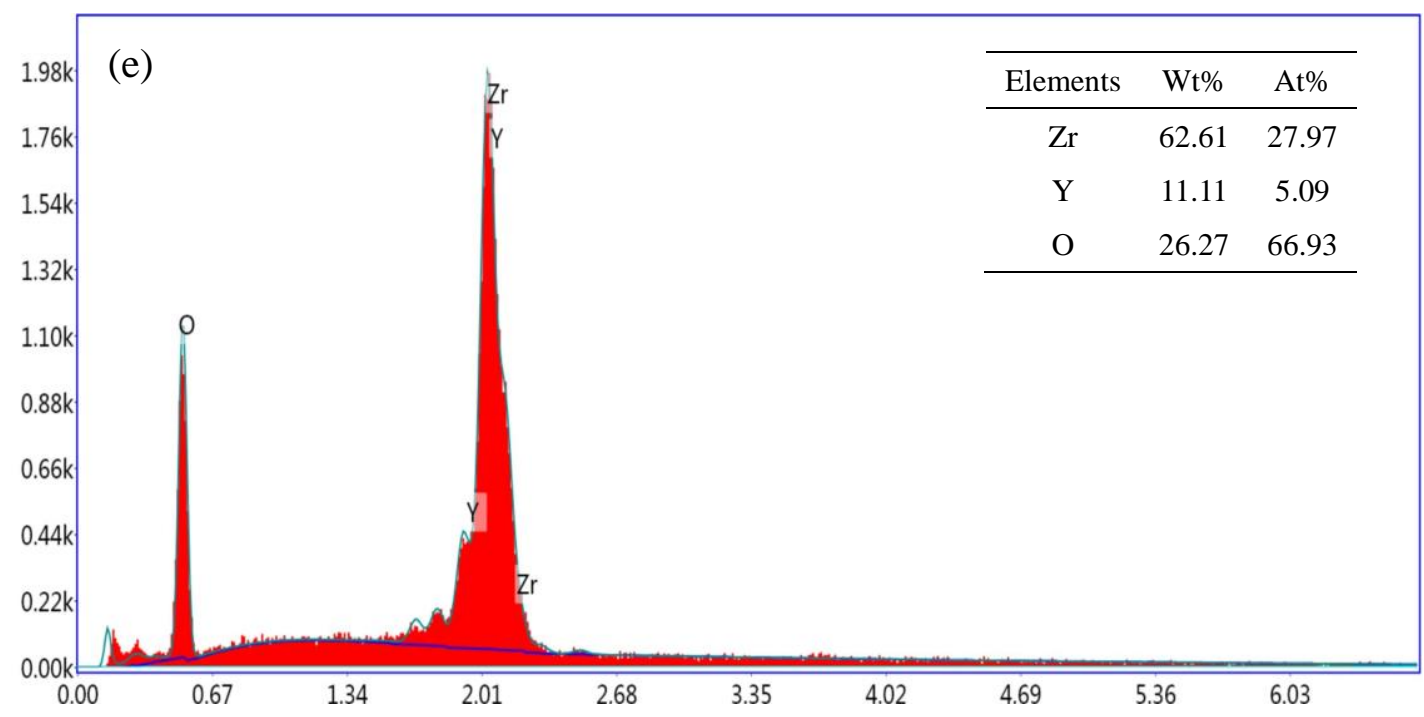

Fig. 5 Microstructure SEM images and of EDS patterns pure and doped tungsten alloys: a) Pure $\mathrm{W}, \mathrm{b}) \mathrm{pH} \mathrm{2,} \mathrm{c)} \mathrm{pH} \mathrm{5,} \mathrm{d)} \mathrm{pH} 8$ and, e) EDS patterns of doping phase.

XRD patterns indicate that $\mathrm{ZrO}_{2}$ particles belong to the stabilized $\mathrm{ZrO}_{2}$ phase, as shown in Fig. 6.

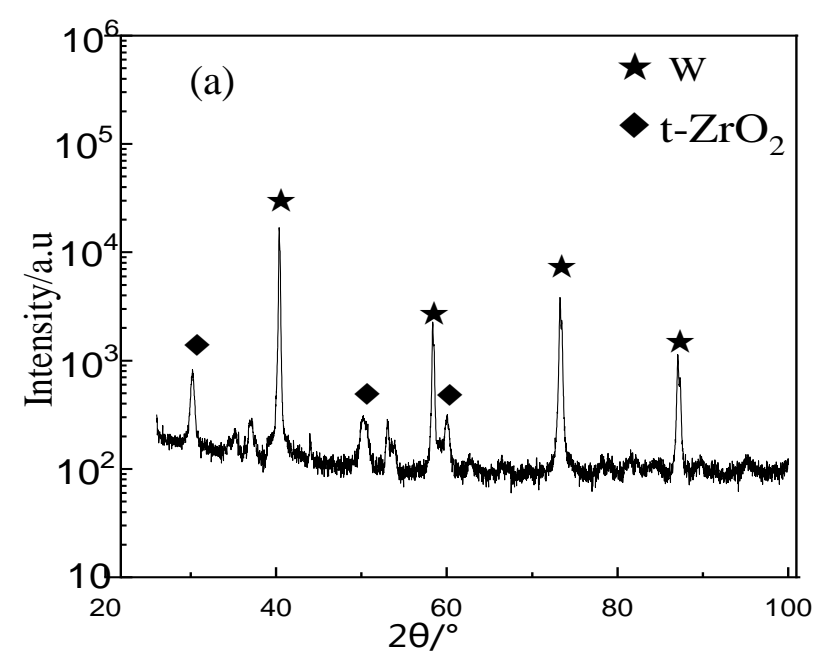

Fig. 6 XRD patterns of test case $\mathrm{pH} 2$ for doped $\mathrm{W}$ sample.

The stabilized $\mathrm{ZrO}_{2}$ phase among alloy was analyzed. At high temperature, stabilized zirconia with $\mathrm{Zr}-\mathrm{O}_{8}$ structure consisted of a zirconium ion and eight equidistant oxygen ions. When the temperature decreased, according to Coordination Theory, due to $\mathrm{rZr}^{4+} / \mathrm{rO}^{2-}=0.564$ (less than 0.732 ), eight - coordinate structure in 
$\mathrm{ZrO}_{2}$ phase would decrease the interspace between oxygen atoms. It would lead to the increasing of the coulomb repulsion between adjacent oxygen - oxygen ions. As a result, the original crystal structure would become unstable, and then promote the transformation from stabilized structure to monoclinic structure with $\mathrm{Zr}^{-} \mathrm{O}_{7}$ [33]

As shown in Fig. 7, $\mathrm{Y}^{3+}$ as stabilizer from $\mathrm{Y}_{2} \mathrm{O}_{3}$ particles could replace the partial $\mathrm{Zr}^{4+}$ atoms in $\mathrm{ZrO}_{2}$ at high temperature, increasing the cation - anion radius ratio. Meanwhile, oxygen vacancies were introduced into the lattice to remain charge neutrality of $\mathrm{ZrO}_{2}$ phase. It would increase the interspace of oxygen - oxygen and reduce the repulsive forces between the local oxygen - oxygen, and then promote the formation of the stability of the $\mathrm{Zr}-\mathrm{O}_{8}$ structure.
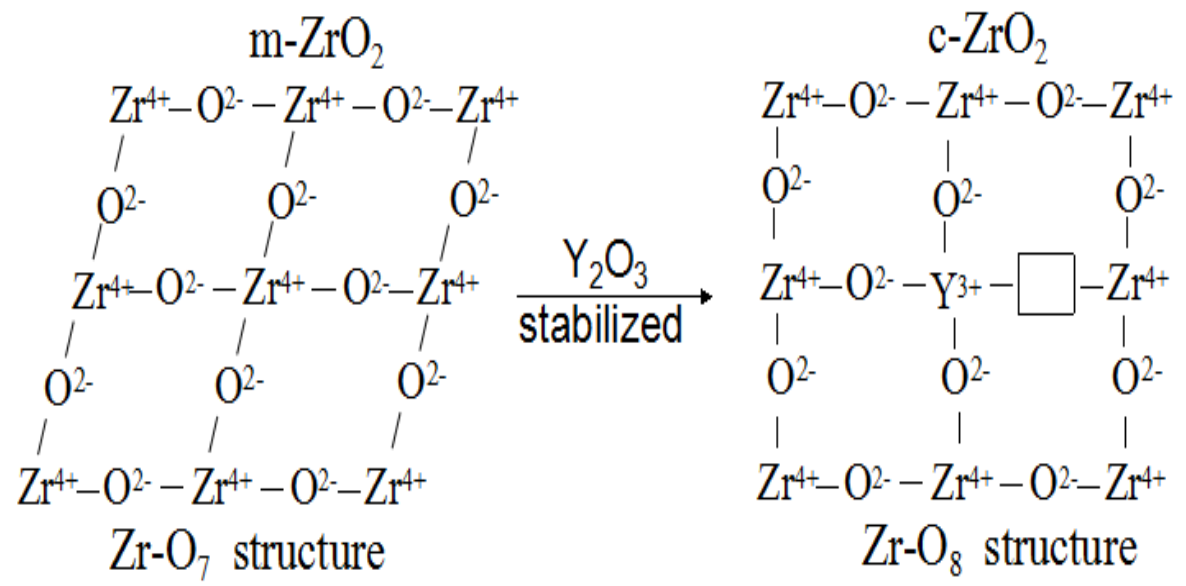

Fig. 7 Schematic flowchart of the cubic yttria - stabilized zirconia.

\section{Mechanical behavior of $\mathrm{W}-\mathrm{Zr}(\mathrm{Y}) \mathrm{O}_{2}$ alloy}

\subsection{Compressive property}

The mechanical properties of pure $\mathrm{W}$ and reinforced $\mathrm{W}$ alloys elaborated under different $\mathrm{pH}$ values are compared in Fig. 8. It can be seen that the pure W possesses the ultimate strain of 0.45 . The ultimate strain and ultimate compressive strength value of $\mathrm{pH} 2$ reach to 0.23 and $1009 \mathrm{MPa}$, respectively. For $\mathrm{pH} 2$ alloy, the ultimate strain is $48.8 \%$, lower than that of pure $\mathrm{W}$ (ductile behaviour). It exhibits highest strain and ultimate compressive strength value compared to $\mathrm{pH} 5$ and 8 alloys. The strain and the ultimate compressive strength value of the alloy increase at lower $\mathrm{pH}$ values. 


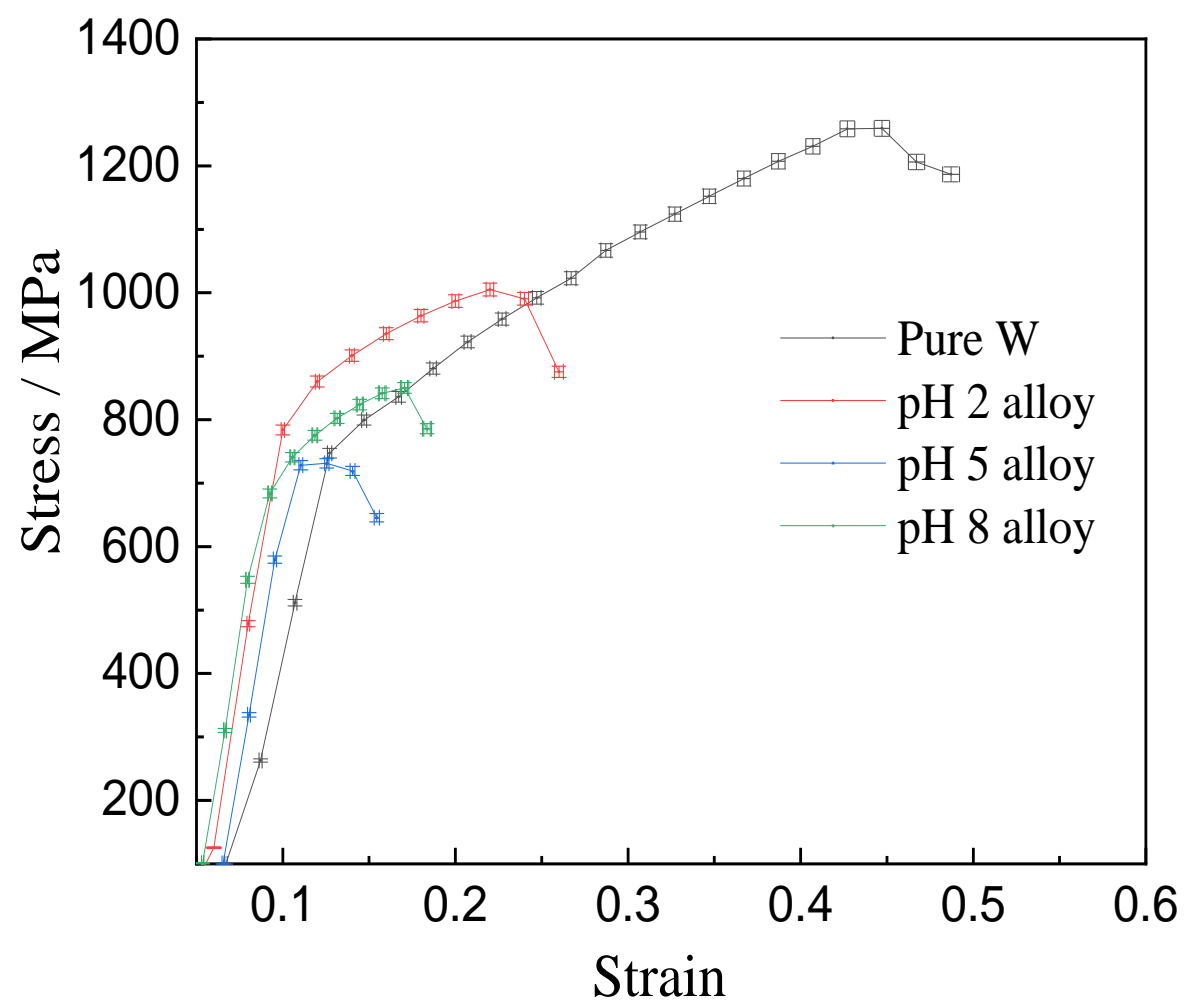

Fig. 8 Compressive stress - strain curves of tungsten alloys.

Table 2 summarizes the evolution of relative density, porosity, micro-hardness and wear resistance of the pure and doped $\mathrm{W}$ alloys versus $\mathrm{pH}$ value. The relative density of the pure $\mathrm{W}$ is about $97.9 \%$, higher compared to pH 2 alloy (i.e. $90.9 \%$ ). The micro-hardness of $\mathrm{pH} 2$ alloy is lower than pure $\mathrm{W}$ due to the pores emerging in the sintering process. It leads to damage the metallic continuity and reduce its effective area. 
1 的

Alloys Relative density (\%) Porosity (\%) doped W alloys.
Micro-hardness (HV)

Abrasion loss (mg) ${ }^{\mathrm{a}^{*}}$

Table 2 Relative density, porosity, micro-hardness and abrasion loss of pure and

\begin{tabular}{|c|c|c|c|c|}
\hline $\mathrm{D}_{9}^{18} \mathrm{ged}$ alloy (pH 2) & $90.9 \pm 0.1$ & $9.1 \pm 0.1$ & $349 \pm 30$ & 34 \\
\hline $\begin{array}{l}20 \\
\text { Deped alloy (pH 5) } \\
22\end{array}$ & $85.9 \pm 0.1$ & $14.1 \pm 0.1$ & $259 \pm 26$ & - \\
\hline $\mathrm{D}_{24}^{23} \mathrm{ed}$ alloy $(\mathrm{pH} 8)$ & $81.6 \pm 0.1$ & $18.4 \pm 0.1$ & $232 \pm 35$ & - \\
\hline $\begin{array}{ll}25 & \\
26 & \text { a* } \\
27 & \\
28 & \text { und }\end{array}$ & loading of 1. & ut using 360 & vaterproof - & aper \\
\hline
\end{tabular}

\subsection{Wear resistance}

Based on the previous analysis, the $\mathrm{pH} 2$ alloy exhibits better mechanical properties. In this part, the influence of zirconia content on wear resistance of $\mathrm{pH} 2$ alloy is studied, summarized in Table 2.

Figs. 9 illustrates the effect of abrasive particle size on wear resistance properties of reinforced W alloys. The weight loss of the alloys decreases with the abrasive particle size of 240, 360, 600 and 800 by using the same loading of $1.40 \mathrm{~N} / \mathrm{mm}^{2}$. The weight loss of reinforced tungsten alloys decreases with $\mathrm{ZrO}_{2}$ fraction from 0 to 3 wt. \% with the same abrasive particles size ( 360 grit $\mathrm{Al}_{2} \mathrm{O}_{3}$ waterproof - abrasive). Then the weight loss of reinforced tungsten alloys increases with the $\mathrm{ZrO}_{2}$ fraction from 3 to 10 wt. $\%$. It proves that $\mathrm{W}-3.0 \% \mathrm{Zr}(\mathrm{Y}) \mathrm{O}_{2}$ alloy possesses the best wear resistance property.

The hardness of $\mathrm{Zr}(\mathrm{Y}) \mathrm{O}_{2}$ particles is higher than the pure $\mathrm{W}$ matrix. In the abrasive wear test, the abrasive particles mainly interact with the $\mathrm{Zr}(\mathrm{Y}) \mathrm{O}_{2}$ particles. 


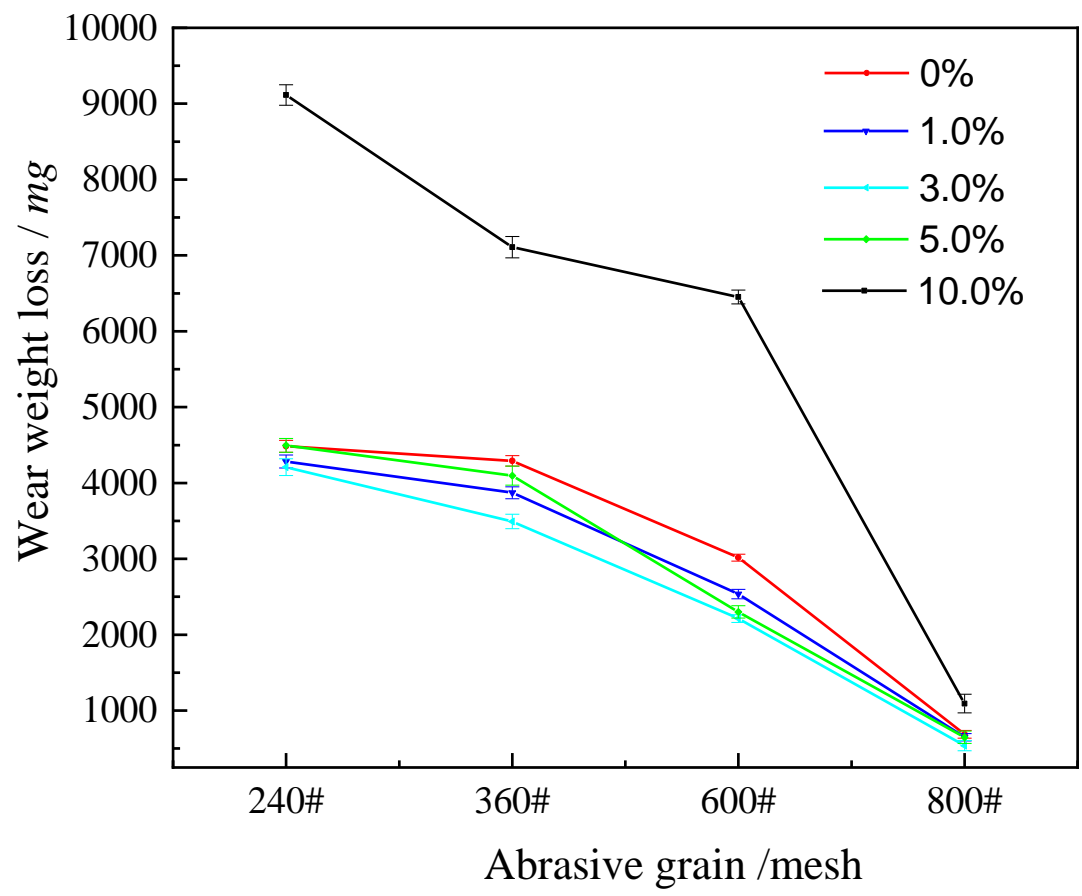

Fig. 9 Effect of abrasive particle size on the wear weight loss of $\mathrm{W}-\mathrm{Zr}(\mathrm{Y}) \mathrm{O}_{2}$ alloys at $1.40 \mathrm{~N} / \mathrm{mm}^{2}$.

\section{Conclusion}

1. Various precursor powders were synthesized under different $\mathrm{pH}$ values $(2,5$ and 8). The morphological structures of the obtained powders were compared. The microstructures as well as mechanical and wear properties of the tungsten alloy elaborated with these powders were investigated.

2. The precursor' powder synthesized under solution with $\mathrm{pH}$ value of 2 


\section{References}

[1] L. Xu, F. Xiao, S. Wei, Y. Zhou, K. Pan, X. Li, J. Li, W. Liu, Development of tungsten heavy alloy reinforced by cubic zirconia through liquid-liquid doping and mechanical alloying methods, International Journal of Refractory Metals and Hard Materials, 78 (2019): 1-8.

[2] F. Xiao, Q. Miao, S. Wei, T. Barriere, G. Cheng, S. Zuo, L. Xu, Uniform nanosized oxide particles dispersion strengthened tungsten alloy fabricated involving hydrothermal method and hot isostatic pressing, Journal of Alloys and Compounds, 824 (2020): 153894.

[3] B. Mamen, J. Song, T. Barriere, J.-C. Gelin, Experimental and numerical analysis of the particle size effect on the densification behaviour of metal injection moulded tungsten parts during sintering, Powder Technology, 270 (2015): 230-243.

[4] F. Xiao, T. Barriere, G. Cheng, Q. Miao, S. Wei, S. Zuo, Y. Yang, L. Xu, Research on the effect of liquid-liquid doping processes on the doped powders and microstructures of $\mathrm{W}-\mathrm{ZrO} 2$ (Y) alloys, Journal of Alloys and Compounds, 855 (2021): 157335.

[5] N. Liu, Z. Dong, Z. Ma, L. Yu, C. Li, C. Liu, Q. Guo, Y. Liu, Eliminating bimodal structures of W-Y2O3 composite nanopowders synthesized by wet chemical method via controlling reaction conditions, Journal of Alloys and Compounds, 774 (2019): 122-128. 
[6] M. Zhao, Z. Zhou, M. Zhong, J. Tan, Y. Lian, X. Liu, Thermal shock behavior of fine grained W-Y2O3 materials fabricated via two different manufacturing technologies, Journal of nuclear materials, 470 (2016): 236-243.

[7] C.-L. Chen, C.-L. Huang, Milling media and alloying effects on synthesis and characteristics of mechanically alloyed ODS heavy tungsten alloys, International Journal of Refractory Metals and Hard Materials, 44 (2014): 19-26.

[8] L. Veleva, R. Schaeublin, M. Battabyal, T. Plociski, N. Baluc, Investigation of microstructure and mechanical properties of $\mathrm{W}-\mathrm{Y}$ and $\mathrm{W}-\mathrm{Y}_{2} \mathrm{O}_{3}$ materials fabricated by powder metallurgy method, International Journal of Refractory Metals and Hard Materials, 50 (2015): 210-216.

[9] M. Qin, J. Yang, Z. Chen, P. Chen, S. Zhao, J. Cheng, P. Cao, B. Jia, G. Chen, L. Zhang, Preparation of intragranular-oxide-strengthened ultrafine-grained tungsten via low-temperature pressureless sintering, Materials Science and Engineering: A, 774 (2020): 138878.

[10] P. Senapati, B. Mishra, A. Parida, Modeling of viscosity for power plant ash slurry at higher concentrations: Effect of solids volume fraction, particle size and hydrodynamic interactions, Powder Technology, 197 (2010): 1-8.

[11] M. A. Yar, S. Wahlberg, H. Bergqvist, H. G. Salem, M. Johnsson, M. Muhammed, Chemically produced nanostructured ODS-lanthanum oxide-tungsten composites sintered by spark plasma, Journal of nuclear materials, 408 (2011): 129-135.

[12] Z. Chen, M. Qin, J. Yang, L. Zhang, B. Jia, X. Qu, Effect of La2O3 addition on the synthesis of tungsten nanopowder via combustion-based method, Journal of Materials Science \& Technology, 58 (2020): 24-33.

[13] F. Xiao, T. Barriere, G. Cheng, Q. Miao, S. Wei, S. Zuo, Z. Huang, L. Xu, Research on preparation process for the in situ nanosized $\mathrm{Zr}$ (Y) $\mathrm{O} 2$ particles dispersion-strengthened tungsten alloy through synthesizing doped hexagonal (NH4) 0.33. WO3, Journal of Alloys and Compounds, 843 (2020): 156059.

[14] Y. Liang, Z. Wu, E. Fu, J. Du, P. Wang, Y. Zhao, Y. Qiu, Z. Hu, Refinement process and mechanisms of tungsten powder by high energy ball milling, International Journal of Refractory Metals and Hard Materials, 67 (2017): 1-8.

[15] U. R. Kiran, M. P. Kumar, M. Sankaranarayana, A. Singh, T. Nandy, High energy milling on tungsten powders, International Journal of Refractory Metals and Hard Materials, 48 (2015): 74-81.

[16] Z. Dong, N. Liu, Z. Ma, C. Liu, Q. Guo, Y. Yamauchi, H. R. Alamri, Z. A. Alothman, M. S. A. Hossain, Y. Liu, Synthesis of nanosized composite powders via a wet chemical process for sintering high performance W-Y2O3 alloy, International Journal of Refractory Metals and Hard Materials, 69 (2017): 266-272.

[17] M. A. Yar, S. Wahlberg, H. Bergqvist, H. G. Salem, M. Johnsson, M. Muhammed, Spark plasma sintering of tungsten-yttrium oxide composites from chemically synthesized nanopowders and microstructural characterization, Journal of nuclear materials, 412 (2011): 227-232.

[18] F. Xiao, L. Xu, Y. Zhou, K. Pan, J. Li, W. Liu,S. Wei, A hybrid microstructure design strategy achieving $\mathrm{W}-\mathrm{ZrO} 2(\mathrm{Y})$ alloy with high compressive strength and critical failure strain, Journal of Alloys and Compounds, 708 (2017): 202-212. 
[19] C. Yuntao, W. Jinshu, L. Wei, W. Xi, Effect of scandia on tungsten oxide powder reduction process, Journal of Rare Earths, 28 (2010): 202-205.

[20] F. Xiao, L. Xu, Y. Zhou, K. Pan, J. Li, W. Liu, S. Wei, Preparation, microstructure, and properties of tungsten alloys reinforced by $\mathrm{ZrO} 2$ particles, International Journal of Refractory Metals and Hard Materials, 64 (2017): 40-46.

[21] Y. Han, J. Fan, T. Liu, H. Cheng, J. Tian, The effect of trace nickel additive and ball milling treatment on the near-full densification behavior of ultrafine tungsten powder, International Journal of Refractory Metals and Hard Materials, 34 (2012): 18-26.

[22] H. Wen, T. Dunqiang, L. Yalei, Y. Xin, L. Lei, L. Deping, Effect of rare earth element cerium on preparation of tungsten powders, Journal of Rare Earths, 33 (2015): 561-566.

[23] A. Heidarzadeh, H. Pouraliakbar, S. Mahdavi, M. R. Jandaghi, Ceramic nanoparticles addition in pure copper plate: FSP approach, microstructure evolution and texture study using EBSD, Ceramics International, 44 (2018): 3128-3133.

[24] A. H. Monazzah, R. Bagheri, S. S. Reihani, H. Pouraliakbar, Toughness enhancement in architecturally modified Al6061-5 vol.\% SiCp laminated composites, International Journal of Damage Mechanics, 24 (2015): 245-262.

[25] F. Xiao, Q. Miao, S. Wei, Z. Li, T. Sun, L. Xu, Microstructure and mechanical properties of $\mathrm{W}-\mathrm{ZrO} 2$ alloys by different preparation techniques, Journal of Alloys and Compounds, 774 (2019): 210-221.

[26] H. Pouraliakbar, A. Nazari, P. Fataei, A. K. Livary, M. Jandaghi, Predicting Charpy impact energy of Al6061/SiCp laminated nanocomposites in crack divider and crack arrester forms, Ceramics International, 39 (2013): 6099-6106.

[27] A. H. Monazzah, H. Pouraliakbar, R. Bagheri, S. S. Reihani, Toughness behavior in roll-bonded laminates based on AA6061/SiCp composites, Materials Science and Engineering: A, 598 (2014): 162-173.

[28] D. Hunyadi, I. Sajó, I. M. Szilágyi, Structure and thermal decomposition of ammonium metatungstate, Journal of Thermal Analysis and Calorimetry, 116 (2014): 329-337.

[29] F. Xiao, Q. Miao, T. Barriere, G. Cheng, S. Zuo, L. Xu, A study on the effect of solution acidity on the microstructure, mechanical, and wear properties of tungsten alloys reinforced by yttria-stabilised zirconia particles, Materials Today Communications, (2021): 102223.

[30] F. Xiao, Q. Miao, S. Wei, W. Liang, X. Fan, K. Pan, L. Xu, Hydrothermal synthesis of nanoplates assembled hierarchical h-WO3 microspheres and phase evolution in preparing cubic $\mathrm{Zr}$ (Y) O2-doped tungsten powders, Advanced Powder Technology, 29 (2018): 2633-2643.

[31] T. Zimmerl, W.-D. Schubert, A. Bicherl, A. Bock, Hydrogen reduction of tungsten oxides: Alkali additions, their effect on the metal nucleation process and potassium bronzes under equilibrium conditions, International Journal of Refractory Metals and Hard Materials, 62 (2017): 87-96.

[32] Y. Hua, J. Wang, J. Ma, S. Chen, C. Lai, D. den Englsen, Effect of yttrium doping on the formation and stability of $\beta$-tungsten powder, International Journal of Refractory Metals and Hard Materials, 72 (2018): 71-77.

[33] Z. Xie, R. Liu, T. Zhang, Q. Fang, C. Liu, X. Liu, G. Luo, Achieving high strength/ductility in bulk W-Zr-Y2O3 alloy plate with hybrid microstructure, Materials \& Design, 107 (2016): 144-152. 
[34] S. Wei, L. Xu, Review on research progress of steel and iron wear-resistant materials, Acta Metall Sin, 56 (2019): 523-538. 